\title{
PENGARUH PEMBINAAN, KEMAMPUAN DAN PERILAKU PENGURUS IKATAN BIDAN INDONESIA PROVINSI BANTEN TERHADAP PELAYANAN PEMBUATAN RE-REGISTRASI SURAT TANDA REGISTRASI (STR) BIDAN DI WILAYAH PROVINSI BANTEN
}

\author{
Esaka Pratala ${ }^{1}$ \\ Dosen Sekolah Tinggi Ilmu Sosial dan Ilmu Politik \\ STISIP Yuppentek Tangerang \\ Email: esaka_pratala@yahoo.com
}

\begin{abstract}
ABSTRAK
Responden pada penelitian ini sebanyak 98 orang bidan yang mengajukan pembuatan re-registrasi Surat Tanda Registrasi (STR). Metode kuantitatif digunakan untuk menjawab masalah dan membuktikan hipotesis. Teknik analisis data yang digunakan untuk membuktikan hipotesis menggunakan analisis statistik inferensial. Hasil uji hipotesis dapat diperoleh informasi, bahwa masing-masing variabel (pembinaan $\mathrm{X}_{1}$, kemampuan $\mathrm{X}_{2}$ dan perilaku $\mathrm{X}_{3}$ ) berpengaruh terhadap pelayanan re-registrasi Surat Tanda Registrasi (STR) bidan di Provinsi Banten, secara simultan juga dapat diketahui bahwa pembinaan, kemampuan dan perilaku pengurus berpengaruh terhadap pelayanan re-registrasi Surat Tanda Registrasi (STR) di Provinsi Banten, Akan tetapi masih adanya variabel epsilon yang bisa mempengaruhi pelayanan re-registrasi Surat Tanda Registrasi (STR). Kondisi saat ini masih ada pengajuan re-registrasi Surat Tanda Registrasi (STR) bidan yang belum selesai, untuk mengoptimalkan pelayanan disarankan agar Pengurus Daerah Ikatan Bidan Indonesia Provinsi Banten dapat melakukan koordinasi secara baik dengan Majelis Tenaga Kesehatan Provinsi (MTKP) Provinsi Banten untuk menyelenggarakan pelayanan one day service dalam rangka pembuatan reregistrasi Surat Tanda Registrasi (STR) bidan bekerjasama dengan Majelis Tenaga Kesehatan Provinsi (MTKP) melalui kegiatan seminar tenaga kesehatan yang diprogramkan secara berkelanjutan 3 (tiga) bulan sekali, sehingga akan adanya prediksi penyelesaian pembuatan re-registrasi Surat Tanda Registrasi (STR) bidan.
\end{abstract}

Kata kunci : Pembinaan, kemampuan, perilaku dan Pelayanan Re-Registrasi STR

\begin{abstract}
Respondents in this study were 98 midwives who applied for re-registration of Registration Certificate. Quantitative methods are used to answer problems and prove hypotheses. Data analysis techniques used to prove hypotheses using inferential statistical analysis. Hypothesis test results can be obtained information, that each variable (Coaching $X_{1}$, ability $X_{2}$ and behavior $X_{3}$ ) affect the reregistration service registration certificate midwives in Banten Province,
\end{abstract}


simultaneously can also be seen that coaching, ability and behavior the management influences the registration registration service service in Banten Province, but there are still epsilon variables that can affect the service for reregistration of the Registration Certificate. the current conditions are still filing reregistration of the Registration Certificate) of midwives that has not been completed, to optimize services it is recommended that the Regional Administrators of the Banten Province Midwives Association be able to coordinate well with the Provincial Health Assembly of Banten Province one day service in the framework of making re-registration of the Registration Certificate midwife in collaboration with the Provincial Health Personnel Council through health personnel seminar activities programmed continuously three months, so that there will be a prediction of completion of re-registration Registration Certificate midwife.

Keywords: Coaching, ability, behavior and Re-Registration STR Services

\section{PENDAHULUAN}

Pengurus Daerah Ikatan Bidan Indonesia Provinsi Banten yang disingkat PD IBI membawahi 8 (delapan) Pengurus Cabang (PC) dan membawahi 68 (enam delapan) pengurus Ranting (PR) serta memiliki 4.622 anggota bidan yang terdaftar pada tahun 2018. PD IBI Provinsi Banten mempunyai tanggung jawab dalam memberikan rekomendasi pembuatan perpanjang Surat Tanda Registrasi (STR) kepada para anggotanya. Berdasarkan data yang diperoleh dari Sekretariat PD IBI Banten, tahun 2017 (Juni-Desember) sampai pada tahun 2018 (Januari-Juni) total pengajuan re-registrasi STR dari tahun 2017 (Juni-Desember) sampai dengan tahun 2018 (Januari-Juni) sebanyak 3.655 pengajuan re-registrasi sedangkan yang sudah jadi sebanyak 2.703. Secara terperinci dapat dilihat pada tabel berikut ini :

\section{Tabel 1.}

Pembuatan Re-Registrasi Surat Tanda Registrasi (STR) Bidan

Provinsi Banten Tahun 2017-2018

\begin{tabular}{|c|c|c|c|c|c|c|c|}
\hline \multirow{3}{*}{$\begin{array}{l}\mathbf{N} \\
\mathbf{0}\end{array}$} & \multirow{3}{*}{ Nama Cabang } & \multirow{3}{*}{$\begin{array}{l}\text { Ang } \\
\text { gota }\end{array}$} & 2017 & 2018 & \multirow{3}{*}{$\begin{array}{l}\text { Total } \\
\text { Pengaju } \\
\text { an }\end{array}$} & \multirow{3}{*}{$\begin{array}{c}\text { Tere } \\
\text { gistr } \\
\text { asi }\end{array}$} & \multirow{3}{*}{$\%$} \\
\hline & & & Juni-Des & Jan-Juni & & & \\
\hline & & & $\begin{array}{c}\text { Re- } \\
\text { Registrasi }\end{array}$ & $\begin{array}{c}\text { Re- } \\
\text { Registrasi }\end{array}$ & & & \\
\hline 1 & Kota Tangerang & 865 & 211 & 404 & 615 & 526 & 60.81 \\
\hline 2 & Kabupaten & 826 & 387 & 330 & 717 & 538 & 65.13 \\
\hline 3 & Tangerang & 325 & 115 & 114 & 229 & 157 & 48.31 \\
\hline 4 & Kota Serang & 336 & 135 & $\begin{array}{l}114 \\
111\end{array}$ & 246 & 208 & $\begin{array}{l}6.31 \\
61.90\end{array}$ \\
\hline & Kabupaten Serang & 570 & 246 & 204 & 450 & 318 & 55.79 \\
\hline 6 & Kota Cilegon & 280 & 128 & 134 & 262 & 240 & 85.71 \\
\hline
\end{tabular}

\begin{tabular}{|c|c|c|c|c|c|c|c|}
\hline 7 & $\begin{array}{l}\text { Kabupaten } \\
\text { Pandeglang } \\
\text { Kabupaten Lebak }\end{array}$ & $\begin{array}{l}754 \\
666\end{array}$ & $\begin{array}{l}358 \\
267\end{array}$ & $\begin{array}{l}270 \\
241\end{array}$ & $\begin{array}{l}628 \\
508\end{array}$ & $\begin{array}{l}476 \\
364\end{array}$ & $\begin{array}{l}63.13 \\
54.65\end{array}$ \\
\hline & $\begin{array}{l}\text { Kabupaten Lebak } \\
\text { Jumlah }\end{array}$ & 4622 & 1847 & 1808 & 3655 & 2703 & 58.48 \\
\hline
\end{tabular}

Sumber : Sekretariat PD IBI Banten, 2018

Dari data yang diperoleh dapat diartikan bahwa jumlah anggota bidan di Provinsi Banten sudah teregistrasi baru mencapai 58,48 \% dari jumlah anggota sebanyak 4.622. Masih banyaknya STR bidan yang belum jadi dan masih banyaknya bidan yang belum teregistrasi menjadi permasalahan yang harus dihadapi oleh PD IBI Provinsi Banten.

Adanya permasalahan tersebut menimbulkan persoalan lainnya yaitu menimbulkan tuntutan dari anggota kepada PD IBI Provinsi Banten untuk meningkatkan kinerja pelayanannya dalam memberikan pelayanan pembuatan reregistrasi STR agar pelayanan berjalan secara optimal yaitu tuntutan untuk memperbaiki pelaksanaan pembinaan yang dilakukan oleh pengurus, peningkatan kemampuan dalam memberikan pelayanan dan perilaku dalam memberikan pelayanan.

Upaya yang dilakukan oleh PD IBI Provinsi Banten untuk meningkatkan kinerja pelayanan Pembuatan re-registrasi STR yaitu dengan melalukan pembinaan kepada para anggotanya melalui pelaksanaan midwifery update (MU) yang diselenggarakan oleh setiap PC IBI dengan 
tujuan agar para anggota mengetahui secara jelas mengenai informasi terkini berkaitan dengan kebidanan salah satunya mengenai, persyaratan, tata cara pengisian format dan prosedur pembuatan re-registrasi STR bidan.

Pelaksanaan midwifery update di Provinsi Banten dilaksanakan pada akhir tahun 2016 disetiap PC IBI, hal tersebut dikarenakan pada awal tahun 2017 per Januari untuk pengajuan berkas permohonan pembuatan re-registrasi STR, seorang bidan harus sudah mengikuti pelaksanaan midwifery update sebagai persyaratan. Akan tetapi pada saat ini pelaksanaan pembinaan yang dilaksanakan disetiap PC IBI belum berjalan secara optimal dikarenakan setiap PC IBI belum melakukan pembinaan kepada seluruh anggotanya. Berdasarkan data yang diperoleh, pembinaan yang dilaksanakan oleh PC IBI di Provinsi Banten berdasarkan data tahun 2016 (November-Desember) sampai dengan tahun 2018 (Januari-Mei) baru 2.196 anggota yang telah mengikuti pembinaan artinya baru 47,51 \% dengan perincian sebagai berikut :

Tabel 2.

Pelaksanaan Pembinaan (Midwifery Update) Per-Cabang IBI

Provinsi Banten Tahun 2016-2018

\begin{tabular}{|c|c|c|c|c|}
\hline No & Nama Cabang & Anggota & $\begin{array}{l}\text { Total } \\
\text { Jumlah } \\
\text { Peserta } \\
\text { Pembinaan }\end{array}$ & $\begin{array}{l}\text { Persen } \\
\%\end{array}$ \\
\hline 1 & Kota Tangerang & 865 & 181 & 20.92 \\
\hline 2 & $\begin{array}{l}\text { Kabupaten } \\
\text { Tangerang }\end{array}$ & 826 & 574 & 69.49 \\
\hline 3 & Kota Tangsel & 325 & 190 & 58.46 \\
\hline 4 & Kota Serang & 336 & 270 & 80.36 \\
\hline 5 & Kabupaten Serang & 570 & 239 & 41.93 \\
\hline 6 & Kota Cilegon & 280 & 120 & 42.86 \\
\hline 7 & $\begin{array}{l}\text { Kabupaten } \\
\text { Pandeglang }\end{array}$ & 754 & 370 & 49.07 \\
\hline 8 & Kabupaten Lebak & 666 & 252 & 37.84 \\
\hline \multicolumn{2}{|c|}{ Jumlah } & 4622 & 2196 & 47.51 \\
\hline
\end{tabular}

Belum optimalnya pelaksanaan pembinaan yang diselenggarakan disetiap Cabang IBI Provinsi Banten dikarenakan lemahnya perencanaan yang dilakukan dalam melaksanakan pembinaan seperti waktu pelaksanaan pembinaan yang sering berbarengan dengan kegiatan hari libur nasional dan kegiatan isidentil lainnya, sehingga pelaksanaan pembinaan menjadi tidak terlaksana sesuai dengan rencana yang ditetapkan.

Dalam memberikan pelayanan dibutuhkan kemampuan pengurus baik secara teknis maupun operasional. Berdasarkan hasil observasi bahwa dalam melakukan penginputan dan validasi data secara komputerisasi sering terjadi kesalahan seperti kesalahan dalam pengetikan nama dan pengisian format validasi.

Selain kemampuan dari pengurus, perilaku dari PD IBI Provinsi Banten dalam memberikan pelayanan re-registrasi STR Bidan menjadi bagian yang penting. Perilaku yang baik dan benar sesuai dengan etika dalam memberikan pelayanan tentunya akan menjadi nilai dan persepsi yang positif dari penerima layanan, sebaliknya etika yang tidak sesuai dengan pemberian layanan akan memberikan penilaian sebaliknya.

Perilaku dari PD IBI Provinsi Banten dalam memberikan layanan bukan hanya dilihat dari etika dalam memberikan pelayanan akan tetapi dilihat juga dari sejauhmana perilaku pengurus dalam memberikan tanggung jawab akan tugas untuk memenuhi kebutuhan bidan untuk menerima pelayanan re-registrasi STR. Pengurus harus mempunyai kepedulian yang tinggi dalam memberikan pelayanan sesuai dengan ruang lingkup pelayanan.

Berdasarkan observasi ditemukan bahwa permasalahan yang dihadapi oleh bidan dalam membuat Re-Registrasi STR sebagai berikut : 1) Proses birokrasi pembuatan Re-Registrasi STR yang cukup panjang dari tingkat PR sampai dengan tingkat pusat. 2) Kondisi lingkungan kerja dan sosial ekonomi pengurus dimasingmasing PC cukup bervariasi, menjadi latar belakang adanya kemampuan dan perilaku 
pengurus yang menangani verifikasi dan validasi data bervariasi sehingga mengakibatkan kinerja dalam melayani proses pembuatan Re-Registrasi STR tidak optimal. 3) Belum optimalnya pelaksanaan pembinaan kepada para anggota disetiap PC dikarenakan pelaksanaan pembinaan yang dilakukan belum menyeluruh kepada anggota. 4) Adanya persepsi negatif dari anggota bidan terhadap perilaku pengurus Ikatan Bidan Indonesia Provinsi Banten dalam memberikan pelayanan ReRegistrasi STR. 5) Belum optimalnya koordinasi berkaitan dengan kebijakan persyaratan re-registrasi STR bidan antara Ikatan Bidan Indonesia (IBI) dengan Majelis Tenaga Kesehatan Indonesia (MTKI) baik ditingkat Pusat maupun ditingkat Daerah. 6) Proses pengiriman STR yang sudah jadi tidak terstruktur sesuai dengan ketentuan, sehingga data anggota sesuai pengajuan dari setiap cabang tidak terkoordinir dengan baik dan tidak adanya kepastian waktu penyelesaian pelayanan.

\section{PERUMUSAN MASALAH DAN HIPOTESIS PENELITIAN}

Rumusan masalah pada penelitian ini yaitu sebagai berikut : 1) Apakah terdapat pengaruh secara signifikan pembinaan terhadap pelayanan re-registrasi Surat Tanda Registrasi (STR) bidan di Provinsi Banten ?. 2) Apakah terdapat pengaruh secara signifikan kemampuan pengurus Ikatan Bidan Indonesia Provinsi Banten terhadap pelayanan re-registrasi Surat Tanda Registrasi (STR) bidan di Provinsi Banten ?. 3) Apakah terdapat pengaruh secara signifikan perilaku pengurus Ikatan Bidan Indonesia Provinsi Banten terhadap pelayanan re-registrasi Surat Tanda Registrasi (STR) bidan di Provinsi Banten ?. 4) Apakah terdapat pengaruh secara signifikan pembinaan, kemampuan dan perilaku pengurus Ikatan Bidan Indonesia Provinsi Banten secara simultan terhadap pelayanan re-registrasi Surat Tanda
Registrasi (STR) bidan di Provinsi Banten ?.

Hipotesis yang diajukan untuk menjawab rumusan masalahnya sebagai berikut : 1) Terdapat pengaruh signifikan antara pembinaan terhadap pelayanan reregistrasi Surat Tanda Registrasi (STR) bidan di Provinsi Banten. 2) Terdapat pengaruh signifikan kemampuan pengurus Ikatan Bidan Indonesia Provinsi Banten terhadap pelayanan re-registrasi Surat Tanda Registrasi (STR) bidan di Provinsi Banten. 3) Terdapat pengaruh signifikan perilaku pengurus Ikatan Bidan Indonesia Provinsi Banten terhadap pelayanan reregistrasi Surat Tanda Registrasi (STR) bidan di Provinsi Banten. 4) Terdapat pengaruh signifikan pembinaan, kemampuan dan perilaku pengurus Ikatan Bidan Indonesia Provinsi Banten secara simultan terhadap pelayanan re-registrasi Surat Tanda Registrasi (STR) bidan di Provinsi Banten.

\section{KERANGKA TEORITIS}

STR merupakan bukti tertulis dari kementerian kesehatan kepada tenaga kesehatan untuk diakui keprofesiannya. Keberadaan bidan sebagai tenaga kesehatan yang belum memiliki STR menjadi isu berskala nasional.

Pelayanan Re-Registrasi STR merupakan salah satu output kinerja dari PD IBI Provinsi Banten, yang berupaya terus menerus meningkatkan pelayanannya melalui pembinaan yang dilakukan kepada para pengurus disemua tingkatan dan anggotanya, dengan tujuan untuk meningkatkan kemampuan baik kemampuan secara teknis maupun konseptual serta perilaku para pengurus khususnya dalam memberikan pelayanan agar kinerja Ikatan Bidan Indonesia Provinsi Banten dalam memberikan pelayanan Re-Registrasi STR terlaksana secara optimal.

Pelayanan Re-Registrasi STR dapat dipengaruhi oleh keberadaan sumber daya 
manusia yang dimiliki PD IBI Provinsi Banten, dalam memberikan pelayanan diperlukan sumber daya manusia yang memiliki kompetensi, kemampuan dan perilaku yang baik dalam memberikan pelayanan. Sehingga yang dijadikan variabel sebagai objek analisis dalam penelitian ini merupakan permasalahan yang berkaitan dengan pembinaan, kemampuan dan perilaku pengurus dalam memberikan pelayanan re-registrasi STR.

Dalam mengukur variabel pembinaan $\left(\mathrm{X}_{1}\right)$ akan menggunakan pendapat yang dikemukakan oleh Saydam (2005: 205), dimana pembinaan dapat dilakukan berdasarkan: 1) Pembinaan mental dan spiritual, 2) Pembinaan loyalitas, 3) Pembinaan hubungan kerja, 4) Pembinaan moril dan semangat kerja, 5) Pembinaan disiplin dan 6) Pembinaan kesejahteraan. Sedangkan untuk variabel kemampuan $\left(\mathrm{X}_{2}\right)$ diukur berdasarkan pendapat yang dikemukakan oleh Gibson (2006 : 21), dimana seseorang dalam organisasi yang mempunyai kemampuan harus mempunyai kriteria kemampuan berinteraksi, konseptual dan administratif. Untuk variabel perilaku pegawai akan mengutip pendapat yang dikemukakan Alvin A. Arens (2006:108) mengenai perilaku etis yang harus dimiliki pegawai yaitu : 1) Tanggung jawab, 2) Kepentingan publik, 3) Integritas, 4) Objektivitas dan indenpendensi, 5) Keseksamaan, dan 6) Ruang lingkup dan sifat pelayanan. Berkaitan dengan variabel terikat (Y) pelayanan pembuatan re-registrasi STR Bidan akan dikukur berdasarkan pendapat yang dikemukakan oleh Lupiyoadi (2010: 147), dimana pelayanan diukur berdasarkan dimensi 1) Bukti langsung, 2) Daya tanggap, 3) Kehandalan, 4) Jaminan dan 5) Empati.

\section{METODE}

Metode penelitian yang digunakan menggunakan desain penelitian kuantitatif dengan jenis asosiatif. Teknik analisis data menggunakan analisis korelasi produk moment, analisis korelasi berganda, analisis koefisien determinasi, analisis regresi sederhana dan analisis regresi berganda. Secara visualisasi gambar desain penelitiannya dapat dilihat sebagai berikut:

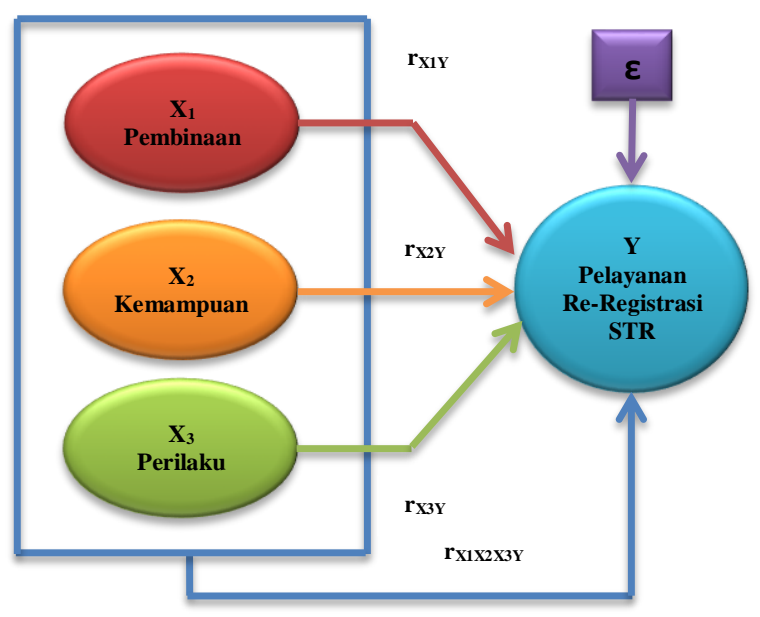

Gambar 1.

Desain Penelitian

Populasi penelitian yang diambil yaitu anggota bidan yang berada diwilayah Provinsi Banten sebanyak 4.622 anggota terdaftar. Teknik penarikan sampel secara acak kepada anggota bidan dengan menggunakan rumus dari Slovin pada taraf kelonggaran $10 \%$ sehingga diperoleh ukuran sampel didalam penelitian ini yaitu sebanyak 98 orang responden. Teknik pengumpulan data yang dipergunakan, mempergunakan alat bantu daftar pertanyaan berupa kuesioner yang bersifat terstruktur. Data yang diperoleh dari hasil jawaban responden akan penulis uji terlebih dahulu guna untuk memenuhi persyaratan uji analisis data, yaitu dengan menggunakan pengujian validitas data, reliabilitas data, normalitas data dan linearitas data.

\section{HASIL PENELITIAN}

\section{Deskripsi Data Variabel Penelitian}

Deskripsi variabel pembinaan $\left(\mathrm{X}_{1}\right)$ diukur berdasarkan dimensi : 1) Pembinaan mental dan spiritual, 2) Pembinaan loyalitas, 3) Pembinaan hubungan kerja, 4) Pembinaan moril dan semangat kerja, 5) 
Pembinaan disiplin, dan 6) Pembinaan karier.

Tabel 3.

Deskripsi Variabel Pembinaan $\left(\mathrm{X}_{1}\right)$ Berdasarkan Faktor Konversi

\begin{tabular}{lccc}
\hline \multicolumn{1}{c}{ Pilihan Jawaban } & $\Sigma$ & $\begin{array}{c}\text { Nilai } \\
\text { Interval }\end{array}$ & Skor Total \\
\hline Sangat Setuju & 177 & 5 & 885 \\
Setuju & 240 & 4 & 960 \\
Ragu-ragu & 172 & 3 & 516 \\
Kurang Setuju & 251 & 2 & 502 \\
Tidak Setuju & 140 & 1 & 140 \\
\hline Jumlah & $\mathbf{9 8 0}$ & Jumlah & $\mathbf{3 0 0 3}$ \\
\hline
\end{tabular}

Sebagai pembanding dipergunakan skor total ideal dengan berasumsi bahwa keseluruhan responden penelitian memberikan tanggapan pada kuesioner mengenai variabel pembinaan memilih opsi sangat setuju (nilai tertinggi 5), sehingga dapat dihitung sebagai berikut : 98 (Responden) x 10 (Jumlah pernyataan kuesioner) x 5 (nilai tertinggi) $=4.900$.

Kemudian untuk memperoleh deskripsi nilai mengenai variabel pembinaan, maka membandingkan nilai skor total dengan nilai skor total ideal, sebagai berikut: $\%$ Pembinaan $=[3.003$ : $4.900] \times 100 \%=61,29 \%$

Sedangkan distribusi penyebaran data tanggapan responden mengenai variabel pembinaan dapat dilihat secara visual pada gambar kurva berikut ini :

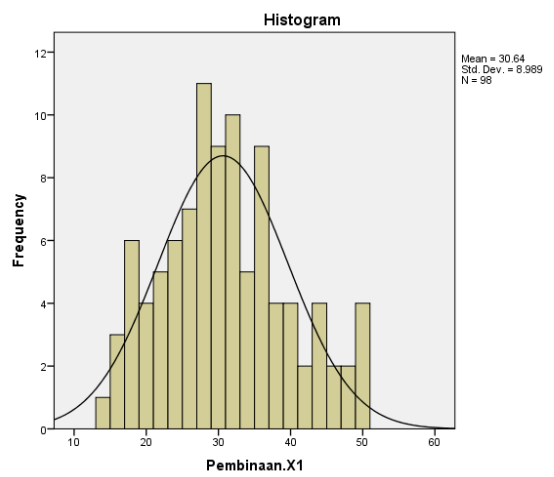

Gambar 2.

Distribusi Penyebaran Data Variabel Pembinaan $\left(\mathrm{X}_{1}\right)$

Deskripsi Variabel Kemampuan $\left(\mathrm{X}_{2}\right)$ diukur berdasarkan dimensi : 1 )
Kemampuan berinteraksi, 2) Kemampuan konseptual, dan 3) Kemampuan administratif.

Tabel 4.

Deskripsi Variabel Kemampuan $\left(\mathrm{X}_{2}\right)$ Berdasarkan Faktor Konversi

\begin{tabular}{lccc}
\hline \multicolumn{1}{c}{ Pilihan Jawaban } & $\Sigma$ & $\begin{array}{c}\text { Nilai } \\
\text { Interval }\end{array}$ & Skor Total \\
\hline Sangat Setuju & 226 & 5 & 1130 \\
Setuju & 197 & 4 & 788 \\
Ragu-ragu & 173 & 3 & 519 \\
Kurang Setuju & 205 & 2 & 410 \\
Tidak Setuju & 179 & 1 & 179 \\
\hline \multirow{2}{*}{ Jumlah } & $\mathbf{9 8 0}$ & Jumlah & $\mathbf{3 0 2 6}$ \\
& \multicolumn{3}{c}{ Skor } \\
\hline
\end{tabular}

Berdasarkan hasil pengolahan data faktor konversi variabel kemampuan dapat diketahui suatu informasi bahwa nilai skor total dari tanggapan responden sebesar 3.026. Sebagai pembanding dipergunakan skor total ideal sama halnya seperti pengolahan data pada variabel sebelumnya dengan nilai skor total ideal 4.900 sebagai berikut : \% Kemampuan $=[3.026: 4.900] \mathrm{x}$ $100 \%=61,67 \%$.

Sedangkan distribusi penyebaran data tanggapan responden mengenai variabel pembinaan dapat dilihat secara visual pada gambar kurva berikut ini :

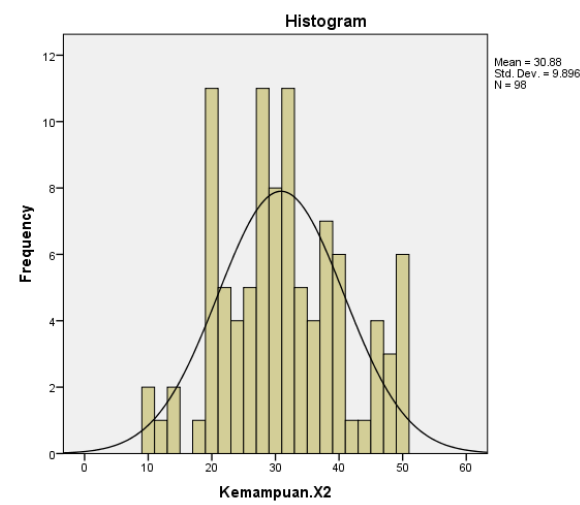

Gambar 3.

Distribusi Penyebaran Data Variabel Kemampuan $\left(\mathrm{X}_{2}\right)$

Variabel perilaku $\left(\mathrm{X}_{3}\right)$ diukur berdasarkan dimensi : 1) Tanggung jawab, 2) Kepentingan Publik, 3) Integritas, 4) Objektivitas dan Independensi, 5) Keseksamaan, 6) Ruang lingkup Kegiatan. 
Tabel 5.

Deskripsi Variabel Perilaku $\left(\mathrm{X}_{3}\right)$ Berdasarkan Faktor Konversi

\begin{tabular}{lccc}
\hline \multicolumn{1}{c}{ Pilihan Jawaban } & $\Sigma$ & $\begin{array}{c}\text { Nilai } \\
\text { Interval }\end{array}$ & Skor Total \\
\hline Sangat Setuju & 151 & 5 & 755 \\
Setuju & 369 & 4 & 1476 \\
Ragu-ragu & 237 & 3 & 711 \\
Kurang Setuju & 151 & 2 & 302 \\
Tidak Setuju & 72 & 1 & 72 \\
\hline Jumlah & $\mathbf{9 8 0}$ & Jumlah & $\mathbf{3 3 1 6}$ \\
\hline
\end{tabular}

Berdasarkan hasil pengolahan data faktor konversi variabel perilaku dapat diketahui suatu informasi bahwa nilai skor total dari tanggapan responden sebesar 3.316. Sebagai pembanding dipergunakan skor total ideal sama halnya seperti pengolahan data pada variabel sebelumnya dengan nilai skor total ideal 4.900 sebagai berikut: \% Perilaku $=[3.316: 4.900] \mathrm{x}$ $100 \%=67,67 \%$. Sedangkan distribusi penyebaran data tanggapan responden mengenai variabel perilaku dapat dilihat secara visual pada gambar kurva berikut ini

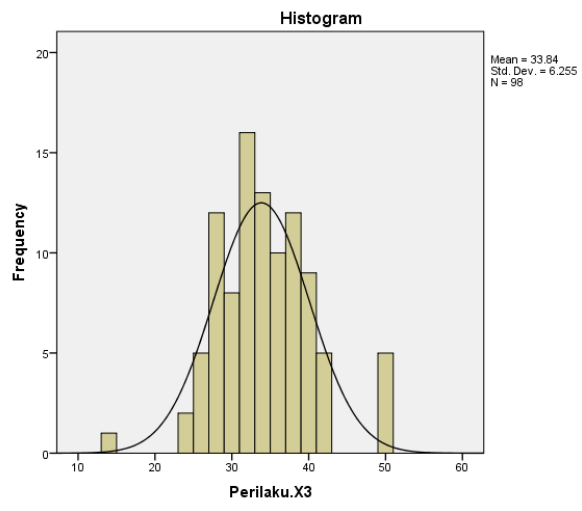

Gambar 4.

Distribusi Penyebaran Data Variabel Perilaku $\left(\mathrm{X}_{3}\right)$

Variabel pelayanan diukur berdasarkan dimensi : 1) Bukti fisik, 2) Kehandalan, 3) Ketanggapan, 4) Jaminan, dan 5) Empati.
Tabel 6.

Deskripsi Variabel Pelayanan (Y) Berdasarkan Faktor Konversi

\begin{tabular}{lccc}
\hline \multicolumn{1}{c}{ Pilihan Jawaban } & $\Sigma$ & $\begin{array}{c}\text { Nilai } \\
\text { Interval }\end{array}$ & Skor Total \\
\hline Sangat Setuju & 157 & 5 & 785 \\
Setuju & 239 & 4 & 956 \\
Ragu-ragu & 210 & 3 & 630 \\
Kurang Setuju & 239 & 2 & 478 \\
Tidak Setuju & 135 & 1 & 135 \\
\hline Jumlah & $\mathbf{9 8 0}$ & Jumlah & $\mathbf{2 9 8 4}$ \\
\hline
\end{tabular}

Berdasarkan hasil pengolahan data faktor konversi variabel pelayanan (Y) dapat diketahui suatu informasi bahwa nilai skor total dari tanggapan responden sebesar 2.984. Sebagai pembanding dipergunakan skor total ideal sama halnya seperti pengolahan data pada variabel sebelumnya dengan nilai skor total ideal 4.900, sebagai berikut: \% pelayanan $(\mathrm{Y})=[2.984: 4.900]$ $\mathrm{x} 100 \%=60,90 \%$.

Sedangkan distribusi penyebaran data tanggapan responden mengenai variabel pelayanan dapat dilihat secara visual pada gambar kurva berikut ini :

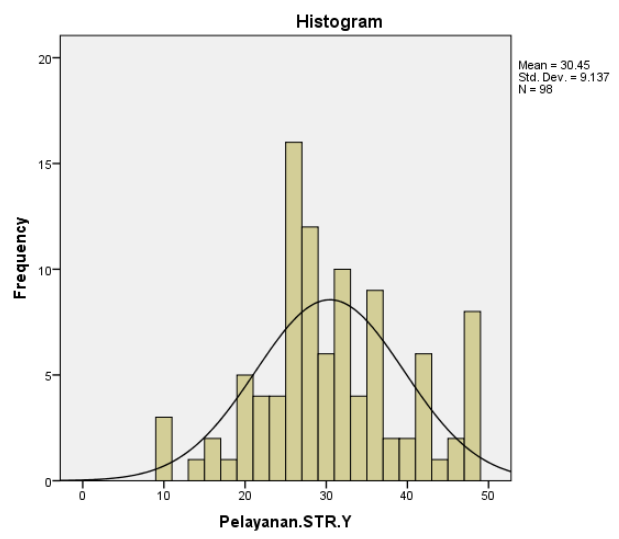

Gambar 5.

Distribusi Penyebaran Data Variabel

Pelayanan Re- Registrasi STR (Y)

Pada tahap pengujian hipotesis pertama digunakan analisis korelasi produk moment dan korelasi berganda. Korelasi variabel pembinaan $\left(\mathrm{X}_{1}\right)$ dengan variabel pelayanan $(\mathrm{Y})$ secara ringkas dapat dilihat pada tabel berikut ini : 
Tabel 7.

Hasil Uji Korelasi Produk Moment Variabel Pembinaan $\left(\mathrm{X}_{1}\right)$ dengan Variabel Pelayanan $\mathrm{Y}$ )

\begin{tabular}{llcc}
\hline & & $\begin{array}{c}\text { Pembinaan } \\
. \text { X1 }\end{array}$ & $\begin{array}{c}\text { Pelayanan. } \\
\text { STR.Y }\end{array}$ \\
\cline { 3 - 4 } Pembinaan & Pearson & 1 & $.494^{* *}$ \\
X1 & Correlation & & .000 \\
& Sig. (2-tailed) & & 98 \\
\hline Pelayanan. & Pearson & $.494^{* *}$ & 1 \\
STR.Y & Correlation & .000 & \\
\multicolumn{1}{r}{} & Sig. (2-tailed) & 98 & 98 \\
\hline **. Correlation is significant at the 0.01 level (2- \\
tailed).
\end{tabular}

Untuk membuktikan hipotesis penelitian dilakukan perhitungan t hitung sebagai berikut:

$t=\frac{r_{y x} \sqrt{N-2}}{\sqrt{1-r_{y x}^{2}}}=\frac{0,494 \sqrt{98-2}}{\sqrt{1-0,494^{2}}}=\frac{0,494.9 .798}{\sqrt{0,756}}=\frac{4,836}{0,870}=5,561$

Korelasi Variabel Kemampuan $\left(\mathrm{X}_{2}\right)$ dengan Variabel Pelayanan (Y) secara ringkas dapat dilihat pada tabel berikut ini:

\section{Tabel 8.}

Hasil Uji Korelasi Produk Moment Variabel Kemampuan $\left(\mathrm{X}_{2}\right)$ dengan Variabel Pelayanan (Y)

$t=\frac{r_{y x} \sqrt{N-2}}{\sqrt{1-r_{y x}^{2}}}=\frac{0,430 \sqrt{98-2}}{\sqrt{1-0,430^{2}}}=\frac{0,430.9 .798}{\sqrt{0,815}}=\frac{4,212}{0,903}=4,665$

Korelasi variabel perilaku $\left(\mathrm{X}_{3}\right)$ dengan variabel pelayanan (Y) secara ringkas dapat dilihat pada tabel berikut ini :

\section{Tabel 9.}

Hasil Uji Korelasi Produk Moment Variabel Perilaku $\left(\mathrm{X}_{3}\right)$ dengan Variabel Pelayanan $(\mathrm{Y})$

$t=\frac{r_{y x} \sqrt{N-2}}{\sqrt{1-r_{y x}^{2}}}=\frac{0,321 \sqrt{98-2}}{\sqrt{1-0,321^{2}}}=\frac{0,321.9 .798}{\sqrt{0,815}}=\frac{3,141}{0,947}=3,316$

Korelasi variabel bebas (Pembinaan $\mathrm{X}_{1}$, Kemampuan $\mathrm{X}_{2}$, dan Perilaku $\mathrm{X}_{3}$ ) dengan Variabel Terikat Pelayanan (Y) maka rumus yang dipergunakan adalah korelasi produk momen berganda, sebagai berikut :

$$
\begin{gathered}
r_{Y X 1 X 2 X 3}=\sqrt{\frac{r_{Y X 1}^{2}+r_{Y X 2}^{2}+r_{Y X 3}^{2}-2 r_{Y X 1} \cdot r_{Y X 2} \cdot r_{Y X 3} \cdot r_{X 1 X 2 X 3}}{1-r_{X 1 X 2 X 3}^{2}}} \\
r_{Y X 1 X 2 \times 3}=\sqrt{\frac{(0,494)^{2}+(0,430)^{2}+(0,321)^{2}-2[(0,494)(0,430)(0,231)(0.618)]}{1-(0,618)^{2}}} \\
r_{Y X 1 X 2 X 3}=\sqrt{\frac{0,531-0,084}{1-(0,618)^{2}}}=\sqrt{\frac{0,042}{0,382}}=\sqrt{0,723}=0,851
\end{gathered}
$$

Untuk mengetahui besarnya pengaruh antara masing-masing variabel bebas terhadap variabel Terikat pelayanan (Y). Secara ringkas hasil analisis koefisien determinasi dirangkum kedalam tabel berikut :

\begin{tabular}{|c|c|c|c|}
\hline Variabel & $\mathbf{r}^{2}$ & KD & Kesimpulan \\
\hline $\begin{array}{lll}\text { Pembinaan } & \left(\mathrm{X}_{1}\right) \quad \text { terhadap } \\
\text { pelayanan }(\mathrm{Y}) & & \end{array}$ & 0,244 & $24,4 \%$ & $\begin{array}{c}\text { Pengaruh Sebesar } \\
24,4 \%\end{array}$ \\
\hline $\begin{array}{l}\text { Kemampuan } \\
\text { pelayanan }(\mathrm{Y})\end{array} \quad\left(\mathrm{X}_{2}\right) \quad$ terhadap & 0,185 & $18,5 \%$ & $\begin{array}{c}\text { Pengaruh Sebesar } \\
18,5 \%\end{array}$ \\
\hline $\begin{array}{l}\text { Perilaku }\left(\mathrm{X}_{3}\right) \text { terhadap pelayanan } \\
(\mathrm{Y})\end{array}$ & 0,103 & $10,3 \%$ & $\begin{array}{c}\text { Pengaruh Sebesar } \\
10,3 \%\end{array}$ \\
\hline $\begin{array}{l}\text { Variabel Bebas }\left(X_{1}, X_{2} \text { dan } X_{3}\right) \\
\text { terhadap variabel terikat }(Y)\end{array}$ & 0,723 & $72,3 \%$ & $\begin{array}{c}\text { Pengaruh } \\
\text { Sebesar 72,3\% } \\
\end{array}$ \\
\hline
\end{tabular}

Tabel 10.

Hasil Uji Koefisien Determinasi (KD)

Hasil regresi variabel pembinaan $\left(\mathrm{X}_{1}\right)$ dengan pelayanan (Y) secara ringkas dapat dilihat pada tabel berikut ini :

\section{Tabel 11.}

\begin{tabular}{|c|c|c|c|}
\hline \multirow{4}{*}{$\begin{array}{l}\text { Kemampu } \\
\text { an.X2 }\end{array}$} & \multirow{4}{*}{$\begin{array}{l}\text { Pearson } \\
\text { Correlation } \\
\text { Sig. (2-tailed) } \\
\text { N }\end{array}$} & $\begin{array}{l}\text { Kemampu } \\
\text { an.X2 }\end{array}$ & $\begin{array}{l}\text { Pelayanan.S } \\
\text { TR.Y }\end{array}$ \\
\hline & & 1 & $.430^{* *}$ \\
\hline & & & .000 \\
\hline & & 98 & 98 \\
\hline \multirow[t]{3}{*}{$\begin{array}{l}\text { Pelayanan. } \\
\text { STR.Y }\end{array}$} & \multirow{3}{*}{$\begin{array}{l}\text { Pearson } \\
\text { Correlation } \\
\text { Sig. (2-tailed) } \\
\text { N }\end{array}$} & $430^{* *}$ & \multirow[t]{2}{*}{1} \\
\hline & & .000 & \\
\hline & & 98 & 98 \\
\hline \multicolumn{4}{|c|}{$* *$. Correlation is significant at the 0.01 level (2-tailed). } \\
\hline \multirow{4}{*}{$\begin{array}{l}\text { Perilaku.X } \\
3\end{array}$} & & $\begin{array}{c}\text { Perilaku. } \\
\text { X3 }\end{array}$ & $\begin{array}{c}\text { Pelayanan. } \\
\text { STR.Y }\end{array}$ \\
\hline & $\begin{array}{l}\text { Pearson } \\
\text { Correlation }\end{array}$ & \multirow[t]{2}{*}{1} & $.321^{* *}$ \\
\hline & Sig. (2-tailed) & & \multirow{2}{*}{$\begin{array}{r}.001 \\
98\end{array}$} \\
\hline & $\mathrm{N}$ & 98 & \\
\hline \multirow[t]{3}{*}{$\begin{array}{l}\text { Pelayanan. } \\
\text { STR.Y }\end{array}$} & $\begin{array}{l}\text { Pearson } \\
\text { Correlation }\end{array}$ & $.321^{* *}$ & \multirow[t]{2}{*}{1} \\
\hline & Sig. (2-tailed) & .001 & \\
\hline & $\mathrm{N}$ & 98 & 98 \\
\hline
\end{tabular}

Hasil Uji Regresi Variabel Pembinaan $\left(\mathrm{X}_{1}\right)$ dengan Pelayanan $(\mathrm{Y})$

Coefficients $^{\mathrm{a}}$ 


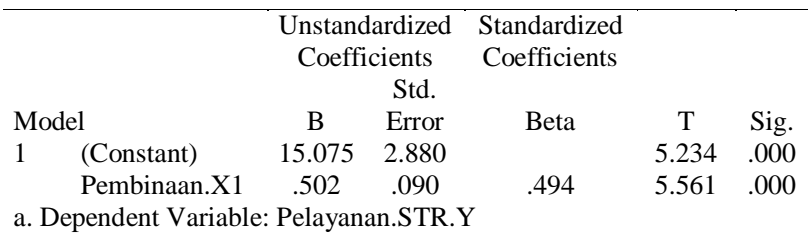

Hasil regresi variabel kemampuan $\left(\mathrm{X}_{2}\right)$ dengan pelayanan $(\mathrm{Y})$ ecara ringkas dapat dilihat pada tabel berikut ini :

\section{Tabel 12.}

Hasil Uji Regresi Variabel Kemampuan (X2) dengan Pelayanan (Y)

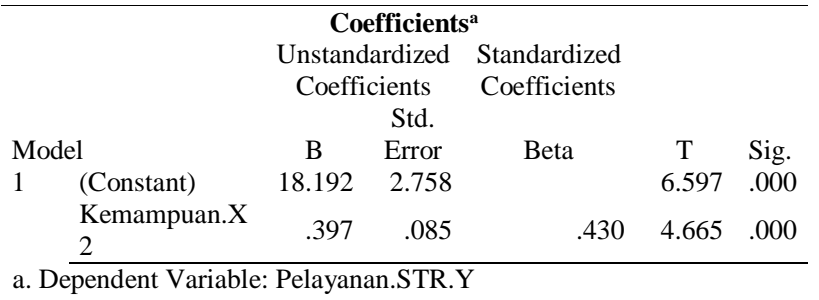

Hasil regresi variabel perilaku $\left(\mathrm{X}_{3}\right)$ dengan pelayanan (Y) secara ringkas dapat dilihat pada tabel berikut ini :

\section{Tabel 13.}

Hasil Uji Regresi Variabel Perilaku $\left(\mathrm{X}_{2}\right)$ dengan Pelayanan (Y)

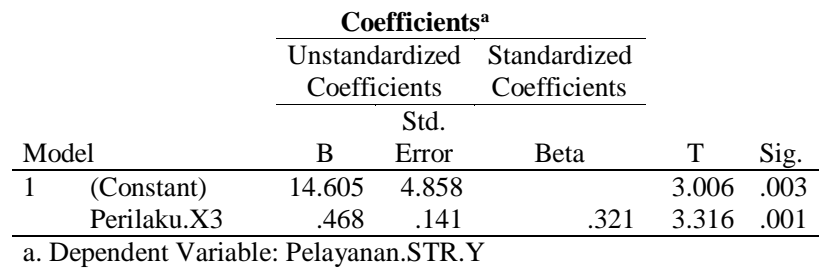

Analisis regresi berganda (pembinaan $\mathrm{X}_{1}$, Kemampuan $\mathrm{X}_{2}$ dan Perilaku $\mathrm{X}_{3}$ ) dengan variabel terikat (Pelayanan $Y$ ) dilakukan untuk membuktikan hipotesis secara simultan. Secara singkat dapat dilihat pada tabel berikut ini :

Tabel 14.

Hasil Uji Regresi Variabel Perilaku (X2) dengan Pelayanan (Y)

\begin{tabular}{cc}
$\begin{array}{c}\text { Unstandardized } \\
\text { Coefficients }\end{array}$ & $\begin{array}{c}\text { Standardized } \\
\text { Coefficients }\end{array}$ \\
\hline
\end{tabular}

\begin{tabular}{crrrrr} 
Perilaku.X3 & .350 & .121 & .239 & 2.893 & .005 \\
\hline a. Dependent Variable: Pelayanan.STR.Y & & &
\end{tabular}

Untuk membuktikan hipotesis penelitian secara simultan, hasil analisis dapat dilihat pada tabel berikut ini :

Tabel 15.

Hasil Analisis Uji F Hitung

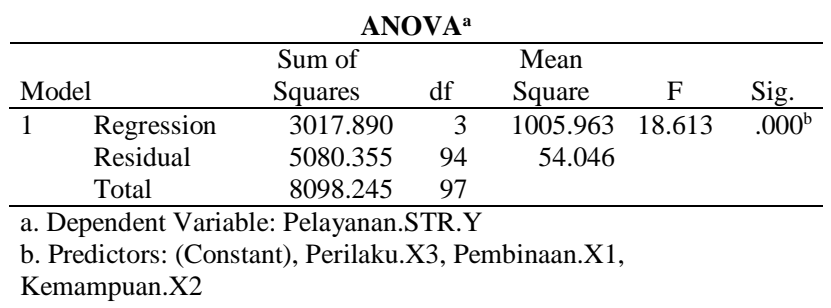

Hasil analisis uji $\mathrm{F}$ diperoleh nilai $\mathrm{F}$ hitung sebesar 18,613. Kemudian nilai $\mathrm{F}$ hitung dibandingkan dengan nilai $\mathrm{F}$ tabel dengan rumus untuk mencari $\mathrm{F}$ tabel adalah ( $\mathrm{k} ; \mathrm{n}-\mathrm{k})$, dimana $\mathrm{k}$ adalah jumlah variabel bebas, dan $\mathrm{n}$ adalah jumlah responden, sehingga dapat dihitung $3 ; 98-3=3 ; 95$. Nilai $\mathrm{F}$ tabel dengan 3 (tiga) variabel bebas (pembinaan $X_{1}$, Kemampuan $X_{2}$ dan Perilaku $\mathrm{X}_{3}$ ) dengan penyebut 95 diperoleh nilai $\mathrm{F}$ tabel sebesar 2,70 (tabel Distribusi F).

\section{PEMBAHASAN}

Berdasarkan hasil pengujian hipotesis mengenai pengaruh pembinaan, kemampuan dan perilaku Pengurus Ikatan Bidan Indonesia Provinsi Banten terhadap pelayanan re-registrasi STR di Wilayah Provinsi Banten dapat diinterpretasikan satu persatu berikut ini :

\section{Pembinaan terhadap Pelayanan}

Hasil korelasi antara pembinaan $\left(\mathrm{X}_{1}\right)$ dengan pelayanan (Y) diperoleh nilai korelasi sebesar 0,494 dengan signifikansi pada $\alpha 0,001$ lebih kecil dari taraf kesalahan $5 \%$. Kemudian nilai korelasi tersebut dimasukan kedalam rumus t hitung, dimana hasil perghitungan $t$ hitung dapat diketahui bahwa nilai dari $\mathrm{t}$ hitung pembinaan $\mathrm{X}_{1}$ Sig.dengan pelayanan $\mathrm{Y}$ yaitu 5,561, nilai .000 tersebut apabila dibandingkan dengan nilai $.003 t$ tabel dengan sampel 98 responden yaitu 
sebesar 2,000 pada taraf signifikansi 0,05 sehingga nilai thitung lebih besar dari pada nilai $\mathrm{t}$ tabel. Dengan demikian maka hipotesis penelitian dapat diterima kebenarannya.

Berdasarkan hasil perhitungan koefisien determinasi, besarnya pengaruh pembinaan terhadap pelayanan sebesar 24,4 $\%$. Prediksi perubahan dari pelayanan berdasarkan analisis regresi linear dapat diperoleh informasi bahwa persamaan regresi antara pembinaan dengan pelayanan memenuhi persamaan $\hat{Y}=15,075+0,502$ $\mathrm{X}_{1}$, nilai tersebut memberikan pengertian bahwa seiring meningkatnya nilai pembinaan maka nilai dari pelayanan akan meningkat.

Hasil analisis memberikan interpretasi bahwa terdapat pengaruh signifikan antara pembinaan terhadap pelayanan re-registrasi STR, hal tersebut memberikan arti bahwa pelaksanaan pembinaan yang dilakukan oleh Ikatan Bidan Indonesia Provinsi Banten melalui midwifery update dapat memberikan kontribusi yang positif bagi peningkatan kompetensi bidan dan pemahaman mengenai prosedur pelayanan re-registrasi STR, oleh karena itu pelaksanaan pembinaan menjadi bagian yang penting untuk diselenggarakan, walaupun dalam pelaksanaannya masih perlu perbaikan untuk dievaluasi. Berdasarkan tanggapan responden penelitian bahwa optimalisasi pelaksanaan pembinaan saat ini baru mencapai $61,29 \%$, artinya masih pada kondisi yang cukup baik dan perlu adanya peningkatan pelaksanaan pembinaan dari mulai proses perencanaan waktu, kompetensi pelatih dan updating pengetahuan terbaru mengenai pelayanan kebidanan.

\section{Kemampuan terhadap Pelayanan}

Hasil korelasi antara kemampuan dengan pelayanan diperoleh nilai korelasi sebesar 0,430 dengan signifikansi pada $\alpha$ 0,000 lebih kecil dari taraf kesalahan $5 \%$. Hasil perghitungan $\mathrm{t}$ hitung dapat diketahui bahwa nilai t hitung kemampuan dengan pelayanan yaitu 4,665, nilai tersebut apabila dibandingkan dengan nilai $\mathrm{t}$ tabel dengan sampel 98 responden yaitu sebesar 2,000 pada taraf signifikansi 0,05 sehingga nilai $t$ hitung lebih besar dari pada nilai t tabel. Berdasarkan hasil analisis maka dapat disimpulkan bahwa hipotesis penelitian dapat diterima kebenarannya.

Hasil perhitungan koefisien determinasi dapat diperoleh informasi bahwa besarnya pengaruh kemampuan dengan pelayanan sebesar 18,5\%. Persamaan regresi linear antara kemampuan dengan pelayanan memenuhi persamaan $\hat{Y}=18,192+0,397$, nilai persamaan tersebut memberikan pengertian bahwa seiring meningkatnya nilai kemampuan maka nilai dari pelayanan akan meningkat.

Hasil analisis memberikan interpretasi bahwa terdapat pengaruh signifikan antara kemampuan terhadap pelayanan reregistrasi STR bidan di Provinsi Banten, hal tersebut memberikan arti bahwa kemampuan pengurus PD IBI Provinsi Banten baik secara berinteraksi, konseptual dan administratif menjadi bagian yang sangat penting dalam memberikan pelayanan re-registrasi STR.

Hasil tanggapan responden pada saat ini bahwa kemampuan yang dimiliki pengurus Ikatan Bidan Indonesia Provinsi Banten memiliki nilai sebesar $61,76 \%$, artinya kemampuan dari pengurus harus lebih dioptimalkan lagi terutama kemampuan dalam hal berinteraksi dengan anggota yang menerima pelayanan dan kemampuan secara konseptual dalam hal menganalisa informasi yang harus disampaikan kepada anggota mengenai aturan-aturan yang berkaitan dengan pelayanan re-registrasi STR serta meningkatkan kemampuan secara administratif dalam melakukan validasi data dan mengoperasionalkan peralatan secara komputerisasi mengikuti perkembangan teknologi dalam memberikan pelayanan. 


\section{Perilaku terhadap Pelayanan}

Hasil korelasi antara perilaku dengan pelayanan diperoleh nilai korelasi sebesar 0,321 dengan signifikansi pada $\alpha 0,001$ lebih kecil dari taraf kesalahan $5 \%$. Hasil perghitungan $\mathrm{t}$ hitung dapat diketahui bahwa nilai dari t hitung perilaku dengan pelayanan yaitu 3,316 , nilai tersebut apabila dibandingkan dengan nilai $\mathrm{t}$ tabel yaitu sebesar 2,000 pada taraf signifikansi 0,05 sehingga nilai thitung lebih besar dari pada nilai $\mathrm{t}$ tabel. Berdasarkan hasil analisis tersebut maka hipotesis penelitian dapat diterima kebenarannya.

Perhitungan koefisien determinasi dapat diperoleh informasi bahwa besarnya pengaruh perilaku dengan pelayanan sebesar 10,3\%. Prediksi perubahan dari pelayanan memenuhi persamaan $\hat{Y}=$ $14,605+0,468$, nilai persamaan tersebut memberikan pengertian bahwa seiring meningkatnya perilaku maka nilai dari pelayanan akan meningkat.

Hasil analisis memberikan interpretasi bahwa terdapat pengaruh signifikan antara perilaku pengurus Ikatan Bidan Indonesia Provinsi Banten terhadap pelayanan reregistrasi STR bidan di Provinsi Banten, hal tersebut memberikan arti bahwa perilaku pengurus Ikatan Bidan Indonesia Provinsi Banten baik secara tanggung jawab, mengutamakan kepentingan anggota, memberikan kepercayaan kepada anggota, bebas dari konflik kepentingan dan memahami pentingnya STR bidan.

Hasil tanggapan responden mengenai perilaku pengurus memiliki nilai sebesar $67,67 \%$, artinya perilaku dari pengurus dalam memberikan pelayanan harus lebih ditingkatkan lagi agar tidak ada lagi persepsi negatif dari anggota terhadap etika pengurus dalam memberikan pelayanan.

\section{Pembinaan, Kemampuan dan Perilaku terhadap Pelayanan Y}

Hasil korelasi berganda diperoleh nilai korelasi pembinaan, kemampuan dan perilaku dengan pelayanan sebesar 0,851 . Sedangkan hasil perhitungan uji F (hitung) untuk membuktikan hipotesis secara simultan diperoleh nilai $\mathrm{F}$ (Hitung) sebesar 18,613 , nilai $\mathrm{F}$ (Hitung) tersebut lebih besar dari nilai $F$ (tabel) sebesar 2,70 dengan demikian didalam pengujian hipotesis memberikan interpretasi hipotesis penelitian dapat diterima kebenarannya. Sedangkan berdsarkan hasil analisis koefisien determinasi dapat diperoleh informasi bahwa secara bersamaan pembinaan, kemampuan dan perilaku terhadap pelayanan berpengaruh sebesar $72,3 \%$, sedangkan sisanya sebesar $27,7 \%$ pelayanan re-registrasi STR bidan dipengaruhi oleh varibel epsilon.

Berdasarkan hasil perhitungan regresi berganda bahwa apabila pembinaan, kemampuan dan variabel perilaku secara bersama-sama berhubungan dengan pelayanan akan memenuhi persamaan $\hat{\mathrm{Y}}=$ $12,420+0,375 \mathrm{X} 1+0,345 \mathrm{X} 2+0,350 \mathrm{X} 3$. Prediksi perubahan dari pelayanan reregistrasi STR dapat dijadikan suatu strategi oleh PD IBI Provinsi Banten untuk meningkatkan pembinaan, kemampuan dan perilaku pengurus dalam upaya meningkatkan pelayanan re-registrasi STR Bidan secara khusus dan meningkatkan kinerja organisasi Ikatan Bidan Provinsi Banten secara umum.

\section{KESIMPULAN}

1. Terdapat pengaruh signifikan pembinaan terhadap pelayanan reregistrasi Surat Tanda Registrasi (STR) bidan di Provinsi Banten.

2. Terdapat pengaruh signifikan kemampuan terhadap pelayanan reregistrasi Surat Tanda Registrasi (STR) bidan di Provinsi Banten.

3. Terdapat pengaruh signifikan perilaku pengurus terhadap pelayanan reregistrasi Surat Tanda Registrasi (STR) bidan di Provinsi Banten.

4. Terdapat pengaruh signifikan secara simultan pembinaan, kemampuan dan perilaku pengurus terhadap pelayanan 
re-registrasi Surat Tanda Registrasi (STR) bidan di Provinsi Banten.

\section{SARAN}

\section{Bagi PD IBI Banten}

a. Pihak PD IBI Provinsi Banten membuat rencana program pembinaan secara terencana berdasarkan program jangka pendek, jangka menengah dan jangka panjang dimulai dari tingkat PC sampai dengan tingkat PR sehnigga pembinaan kepada anggota dapat berkesinambungan tidak hanya sebatas kegiatan.

b. PD IBI Banten agar lebih meningkatkan lagi kemampuan secara konseptual terutama dalam memahami prosedur, mekanisme dan aturan-aturan yang berkaitan dengan pengurusan STR dan meningkatkan kemampuan secara administratif yang berkaitan dengan verifikasi data dan validasi data serta mengoperasionalkan peralatan secara komputerisasi mengikuti perkembangan teknologi dalam memberikan pelayanan.

c. PD IBI Banten memahami tugas pokok dan fungsinya sebagai pengurus sesuai dengan bidang tugasnya. Selain itu bahwa keberadaan sumber daya manusia merupakan asset utama yang dimiliki oleh Ikatan Bidan Indonesia Provinsi Banten, oleh karena itu tingkat kesejahteraan pengurus yang berada di bagian pelayanan STR dapat ditingkatkan kesejahteraannya agar dalam memberikan pelayanan tidak memberikan perilaku yang tidak sesuai dengan kode etik perilaku.

d. PD IBI Provinsi Banten berkoordinasi dengan Majelis Tenaga Kesehatan Provinsi
(MTKP) Provinsi Banten menyelenggarakan pelayanan one day service pembuatan STR bidan melalui kegiatan seminar tenaga kesehatan yang diprogramkan secara berkelanjutan per 3 (tiga) bulan sekali.

\section{Bagi Pihak Lain}

Hasil penelitian masih adanya variabel lain diluar variabel pembinaan, kemampuan, dan perilaku yang bisa mempengaruhi pelayanan STR, oleh karena itu untuk mengetahui lebih detail mengenai variabel-variebel yang dapat mempengaruhi pelayanan STR, disarankan agar adanya penelitian lanjutan berkaitan dengan pelayanan STR di Provinsi Banten.

\section{DAFTAR PUSTAKA}

Amin, Wibowo. 2010. Manajemen Pengembangan Model Konseptual. Gramedia Pustaka Utama. Jakarta.

Boediono. 2009. Pelayanan Prima. Rineka Cipta. Jakarta.

Ghazali, Syadam. 2005. Manajemen Sumber Daya Manusia. Djmabatan. Jakarta.

Gibson, James L., Ivancevich, John M., dan Donenely James H. Jr. 2006. Organisasi dan Manajemen. Edisi Keempat. Penerbit Erlangga. Jakarta

Handoko, T Hani. 2011. Manajemen Personalia dan Sumber Daya Manusia. BPFE. Yogyakarta.

Kreitner, Robert dan Kinicki, Angelo. 2005. Perilaku Organisasi, buku 1 dan 2. Salemba Empat. Jakarta

Lupiyoadi, Rambat. 2010. Manajemen Pemasaran Jasa ; Teori dan Praktik Edisi Revisi. Salemba Empat. Jakarta 
Moenir H.A.S. 2010. Manajemen Pelayanan Umum Indonesia. Bumi Aksara. Jakarta.

Pasolog, Harbani 2010. Teori Administrasi Publik: Cetakan ke Empat. Alfabeta. Bandung.

Robbins, Stephen P dan Merry Coulter. 2010. Manajemen Jilid 1. Erlangga. Jakarta.

Sedarmayanti. 2013. Manajemen Sumber Daya Manusia : Reformasi Birokrasi dan Manajemen Pegawai Negeri Sipil. Aditama. Bandung.

Sigit, Soehardi. 2003. Esensi Perilaku Organisasional. BPFE. Yogyakarta..

Sinambela, Lijan, Poltak. 2010. Reformasi Pelayanan Publik (Teori, Kebijakan, dan Implementasi). Bumi Aksara. Jakarta.

Sugiyono. 2010. Metode Penelitian Bisnis (Best Seller). Alfabeta. Bandung. 2012. Statistika Untuk Penelitian. Alfabeta. Bandung.

Sutrisno, Edi. 2010. Budaya Organiasi. PT. Kencana. Jakarta.

Thoha, Miftah. 2003. Perilaku Organisasi, Konsep Dasar dan Aplikasinya. Raja Grafindo Persada. Jakarta.

\section{Jurnal :}

Christian Van Nieuwerburgh. 2016. Editorial, Coaching : $A N$ International Journal of Theory, Research And Pratice. 9 (2). 8992.doi. 10.1080/17521882.2016.1213006.

Icek Ajzen. 2011. The Theory of Planned Behavior: Reaction and Reflections, Psychology and Health. 26 (9). 11131127. doi. 10.1080 / 08870446.2011. 613995.

Jeff Bialik. 2017. Creating a Taxonomy of Outcomes in a Comprehensive Nonprofit Human Service Organization, Human Sercive
Organization : Management, Leadership dan Governance. 41 (3), 201-206. doi. 10.1080 / 23303131. 2017. 1321283.

Marcia Taylor and Dori Finley. 2016. Strategic Human Resource Management in U.S. Luxury Resort-A Case Study, Juornal Of Human Resorces in Hospitality and Tourism. 8 (1), 82-92. doi. : $10.1080 / 153328408802274460$.

\section{Peraturan Perundang-undangan :}

Permenkes Nomor 46 Tahun 2013 tentang Registrasi Tenaga Kesehatan.

Undang-undang Nomor 36 Tahun 2014 tentang Tenaga Kesehatan. 